\title{
Detection of immune complexes in serum of patients with ankylosing spondylitis
}

\author{
VALERIE CORRIGALL, G. S. PANAYI, ARLEEN UNGER, R. N. POSTON ${ }^{1}$, \\ AND B. D. WILLIAMS
}

From the Departments of Medicine and Pathology, ${ }^{1}$ Guy's Hospital Medical School, London SEI 9RT

SUMMARY Immune complexes were measured in the sera of 18 patients with ankylosing spondylitis and 5 normal control subjects by their ability to inhibit antibody-mediated lymphocyte-induced cytotoxicity. 11 of the spondylitic and none of the control sera contained circulating complexes. Fractionation of sera on Sephadex G-200 showed that complexes were of two molecular sizes, one of intermediate and the other of large molecular weight. The presence of immune complexes did not correlate with activity of disease or the presence of peripheral arthritis although the one patient with polyarthritis had the highest level of complexes detected in this study. The nature of the antigen in these antigen-antibody complexes is of great interest since it may provide evidence of the aetiological agent in the disease.

Although the aetiology of ankylosing spondylitis (AS) is unknown, there is increasing evidence that immunological mechanisms may be involved. Among this evidence may be included (1) hypergammaglobulinaemia and abnormalities of serum complement (Kinsella et al., 1975); (2) the presence of IgG anti-immunoglobulins in serum (Arana et al., 1975); and (3) the association between AS and HLA B27 histocompatibility antigen (Brewerton et al., 1973), which may imply that an immune response gene may be active in the disease.
(Panayi et al., 1977). In brief, Chang human liver cells (Flow Laboratories) were labelled with ${ }^{51} \mathrm{Cr}$ sodium chromate (Radio Chemical Centre, Amersham), and incubated with rabbit anti-Chang antiserum (final dilution $10^{-5}$ ) and Triosil-Ficoll purified human peripheral blood lymphocytes (lymphocyte/target cell ratio $30 / 1$ ) for 4 hours at $37^{\circ} \mathrm{C}$. The inhibition of cytotoxicity by sera from normal subjects, patients with AS, or aggregated human IgG (aggregated by heating (HAGG) at $63^{\circ} \mathrm{C}$ for $20 \mathrm{~min}$ ) was expressed as:

$$
\% \text { inhibition }=\frac{\begin{array}{l}
\% \text { cytotoxicity in } \\
\text { control medium }
\end{array}-\begin{array}{c}
\% \text { cytotoxicity in } \\
\text { serum or HAGG }
\end{array}}{\% \text { cytotoxicity in control medium }} \times 100 \text {. }
$$

Since the inflammatory changes in AS are not confined to the sacroiliac and vertebral joints but may also affect peripheral joints, the aortic valve, and the uveal tract, circulating immune complexes may be present. This work detected and measured circulating immune complexes in AS by the inhibition of antibody-mediated lymphocyte-induced cytotoxicity (AMLC).

\section{Materials and methods}

\section{THE CYTOTOXIC SYSTEM}

This system has been described in detail elsewhere

Accepted for publication August 24, 1977

Correspondence to Dr G. S. Panayi
The per cent inhibition of cytotoxicity produced by a particular serum was compared to the inhibition produced by HAGG in parallel and simultaneous experiments so that results of inhibition were expressed as ' $\mu \mathrm{g} / \mathrm{ml}$ of HAGG equivalents'. In every experiment normal and AS sera were included.

\section{PATIENTS AND SERA}

Eighteen patients with AS (all having HLA B27 histocompatibility antigen) and 5 control subjects were studied. Sera were separated within 3 hours of bleeding and stored in $0.5 \mathrm{ml}$ aliquots in liquid nitrogen. Preliminary experiments showed that storage of serum at $-20^{\circ} \mathrm{C}$ generated inhibiting activity probably because of formation of aggregates 
of IgG. Sera were tested within one month. Aliquots of serum were thawed once and used on the same day.

\section{CHROMATOGRAPHY OF SERA}

Sera were fractionated on a $100 \mathrm{~cm} \times 2.5 \mathrm{~cm}$ column of Sephadex G-200 (Pharmacia) at an elution rate of $14 \mathrm{ml} / \mathrm{h}$ with collection of 20 -minute fractions. The optical density $\left(\mathrm{E}^{1}{ }_{280} \mathrm{~cm}\right)$ of fractions was read on a Perkin-Elmer spectrophotometer. The elution buffer was phosphate-buffered saline, pH 7.2, containing $0.05 \%$ sodium azide. While $0.5 \mathrm{ml}$ of a particular serum was being fractionated, another $0.5 \mathrm{ml}$ was diluted to $2.5 \mathrm{ml}$ with elution buffer and stood at room temperature in order to control the changes due to thawing, buffer dilution, and temperature changes which the fractionated aliquot would undergo during elution. At the end of chromography, designated fractions and the diluted aliquot were concentrated back to $0.5 \mathrm{ml}$ by Amicon 'centriflo' membrane concentration before being tested for their ability to inhibit AMLC.

Sera and their chromatographic fractions were tested for inhibition of AMLC at a dilution of 1:10.

\section{CALIBRATION OF SEPHADEX G-200 COLUMN}

The column was calibrated with the following substances: human serum albumin (70000 daltons), human IgG (160000 daltons), carcinoembryonic antigen (200 000 daltons), and human IgM (1 000000 daltons).

Table 1 Dose-related inhibition of antibody-mediated lymphocyte-induced cytotoxicity by heat aggregated human IgG.

\begin{tabular}{lll}
\hline $\begin{array}{l}\text { Concentration of } \\
\text { heat aggregated } \\
\text { IgG }(\mu \mathrm{g} / \mathrm{ml})\end{array}$ & $\begin{array}{l}\text { \% specific relesease } \\
\text { of }{ }^{51} \text { Cr-chromate }\end{array}$ & $\begin{array}{l}\% \text { inhibition of } \\
\text { cytotoxicity }\end{array}$ \\
\hline 0 & & \\
\hline 0.1 & $20 \cdot 1$ & - \\
$10 \cdot 0$ & $21 \cdot 3$ & 0 \\
$100 \cdot 0$ & $18 \cdot 5$ & $7 \cdot 7$ \\
\hline
\end{tabular}

\section{Results}

INHIBITION OF CYTOTOXICITY BY HAGG

The inhibition of AMLC produced by various con $\overrightarrow{\vec{P}}$ centrations of HAGG is a quantitative one (Panaxd et al., 1977) as can be seen from Table 1. Therefores during each experiment graphs of per cent inhibition of cytotoxicity by various concentrations of HAGब were constructed. From such graphs the per cents inhibition given by a serum or any of its fractions. could be expressed as equivalents of HAGG $(\mu \mathrm{g} / \mathrm{ml})$.

\section{DETECTION OF COMPLEXES IN SERA}

Of $18 \mathrm{AS}$ sera, 11 contained circulating immune complexes while none of the 5 control sera did sol (Table 2). There were no significant differences in those patients with AS who had none (group A small amounts (group B), or large amounts (group C) of circulating immune complexes in their serum with respect to age, duration of disease, ESR, or clinical measurements such as finger-to-floor distance. total spinal movement, or chest expansion. One patient, in group $\mathrm{C}$, with peripheral inflammator joint involvement, had the highest detected corrcentration of complexes $(68.7 \mu \mathrm{g} / \mathrm{ml}$ HAG\& equivalents). No patients had active uveitis at the time of the study.

FRACTIONATION OF SERA ON SEPHADEX G-200

Six AS and 5 control sera were fractionated of Sephadex G-200. None of the control sera showed inhibiting activity after fractionation and the profile of eluted protein is shown in Fig. 1a. 2 of the sera contained no inhibiting material before or after fractionation and the elution profile was similar that of control sera. None of these sera, which we negative for complexes, showed any inhibiting activity after dilution with elution buffer.

Four AS sera contained inhibiting activity before and after fractionation. One of them had a proter elution profile similar to the control sera and had inhibiting material in fractions 35 and 41 only. The

Table 2 Detection of circulating immune complexes in the serum of 18 patients with ankylosing spondylitis. The patients have been divided into three groups depending on the concentration of complexes in their serum. There was no difference in age, duration of disease, or ESR between the groups. 5 sera from normal subjects examined at the same time had no detectable complexes

\begin{tabular}{|c|c|c|c|c|c|c|}
\hline Group & $\begin{array}{l}\text { Concentration of } \\
\text { complexes }(\mu g / m l) \\
H A G G(\text { mean } \pm S D)\end{array}$ & $n$ & Male: female & $\begin{array}{l}\text { Age (years) } \\
\text { (mean and range) }\end{array}$ & $\begin{array}{l}\text { Duration of } \\
\text { disease (years) } \\
\text { (mean and range) }\end{array}$ & $\begin{array}{l}E S R \\
(\text { mean } \pm S D)\end{array}$ \\
\hline $\begin{array}{l}A \\
B \\
C\end{array}$ & $\begin{array}{l}0 \\
13 \cdot 8 \pm 3 \cdot 5 \\
49 \cdot 2 \pm 16 \cdot 5\end{array}$ & $\begin{array}{l}7 \\
5 \\
6\end{array}$ & $\begin{array}{l}7: 0 \\
3: 2 \\
5: 1\end{array}$ & $\begin{array}{l}46 \cdot 0(28-56) \\
42 \cdot 0(25-71) \\
37 \cdot 0(26-51)\end{array}$ & $\begin{array}{l}15 \cdot 3(10-30) \\
12 \cdot 8(4-21) \\
15 \cdot 8(3-32)\end{array}$ & $\begin{array}{l}27 \pm 10 \\
26 \pm 14 \\
30 \pm 12\end{array}$ \\
\hline
\end{tabular}

HAGF = heat aggregated human IgG. 
remaining 3 sera had elution profiles different from all the other sera (Fig. 1a) in that there was increased protein in fractions 35 to 40 inclusive. Assay of fractions for inhibiting material showed that such inhibiting material was present in fractions 32 to 37

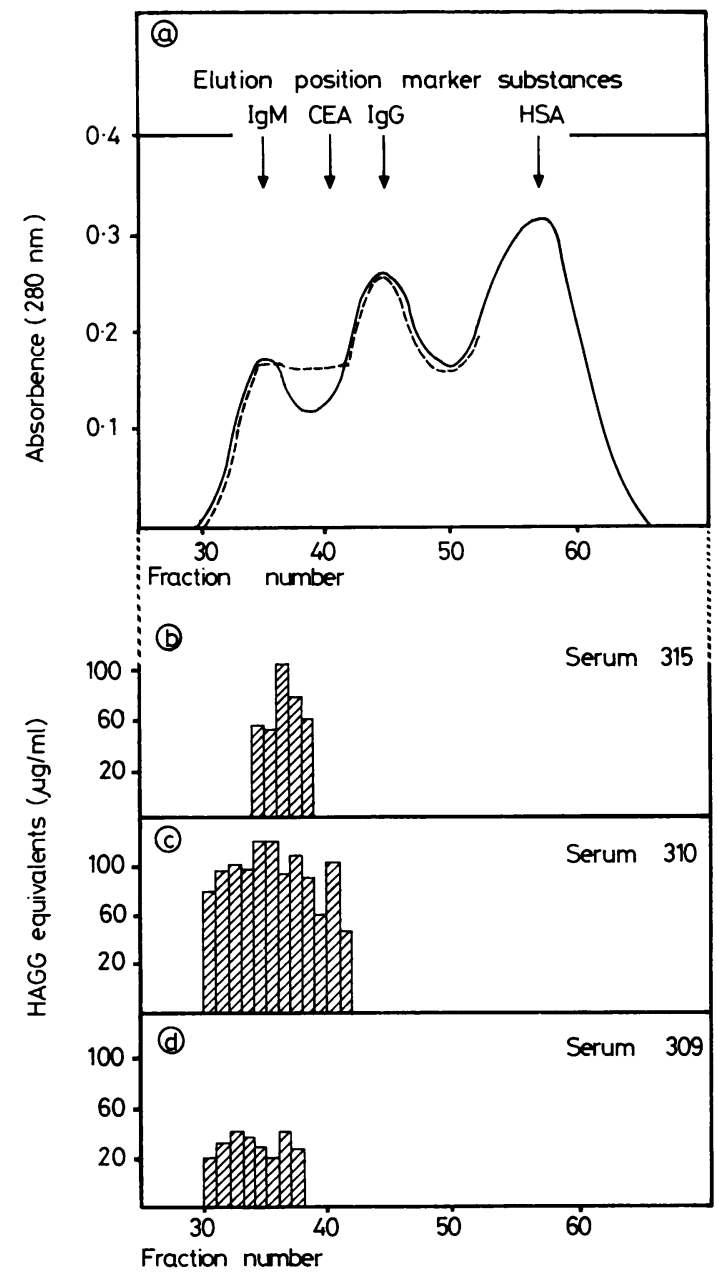

Fig. 1 Fractionation of $0.5 \mathrm{ml}$ of serum from 6 AS patients and 5 normal subjects on Sephadex G-200 column. For each fraction collected the absorbence $(280 \mathrm{~nm})$ and the presence of immune complexes was measured. The column was calibrated with IgM, IgG, HSA (human serum albumin), and CEA (carcinoembryonic antigen). (a) Profile of eluted proteins:for 5 control and $2 A S$ sera with no immune complexes and for one $A S$ serum with complexes;------ for remaining $3 A S$ sera which contained complexes showing increased eluted protein in fractions 35-40 inclusive. $(b, c, d)$ Distribution and amount of complexes in $3 A S$ sera, with elution profile --_.-- shown in a. Columns represent concentration of complexes expressed as $H A G G$ equivalents $(\mu \mathrm{g} / \mathrm{ml})$ in each fraction. and distributed in two peaks (Fig. $1 b, c, d$ ). When compared to the elution volume of substances of known molecular weight, the molcular weights of the two peaks corresponded to molecular weights of just below $10^{6}$ and much greater than $10^{6}$ daltons respectively.

\section{EFFECT OF IgG ON ALMC}

In some sera the concentration of inhibiting material was much greater after fractionation than before. Thus the sera shown in Fig. $1 b, c$, and $d$ contained $32 \cdot 8,68 \cdot 7$, and $28.4 \mu \mathrm{g} / \mathrm{ml}$ HAGG equivalents of complexes. Two possibilities were investigated. First, the serum may have contained anti-Chang cell antibodies (Panayi, 1976), but separate experiments showed that no sera did so. The presence of such antibodies would produce falsely low inhibiting activity in whole serum because it would increase the amount of cytotoxic antibody present and therefore require more complexes for the same degree of inhibition as the standard HAGG. Second, fractionation of sera may produce disturbances in the bioassay by its ability to fractionate whole serum into various components. Fig. 2 shows indeed that normal monomeric IgG is capable of enhancing AMLC while polymeric or aggregated IgG inhibits it. Thus, removal of monomeric IgG during fractionation would produce an apparent increase in the concentration of inhibiting material since while testing whole serum the IgG present in it would tend to counteract the inhibiting activity of the contained complexes.

\section{Discussion}

AMLC may be inhibited by aggregated IgG (Wisløff et al., 1974) or by soluble immune complexes. The inhibiting activity shown in some AS sera and their chromatographic fractions may therefore be due to aggregates of IgG or to circulating immune complexes. The following reasons are given for believing that the inhibitory activity shown in this study is due to complexes and not aggregates. (1) Although freezing of serum can cause aggregation of IgG (Hansson, 1968), the absence of inhibiting activity before and after storage in control sera and some sera of patients with AS renders this unlikely. (2) Dilution of sera with elution buffer and concentration of chromatographic fractions by Amicon ultrafiltration is unlikely to have generated inhibiting activity since those sera which did not show inhibition before such manipulations did not do so afterwards. (3) For the same reason, the chromatographic separation itself cannot have generated inhibiting activity by, for example, aggregation of IgG. 


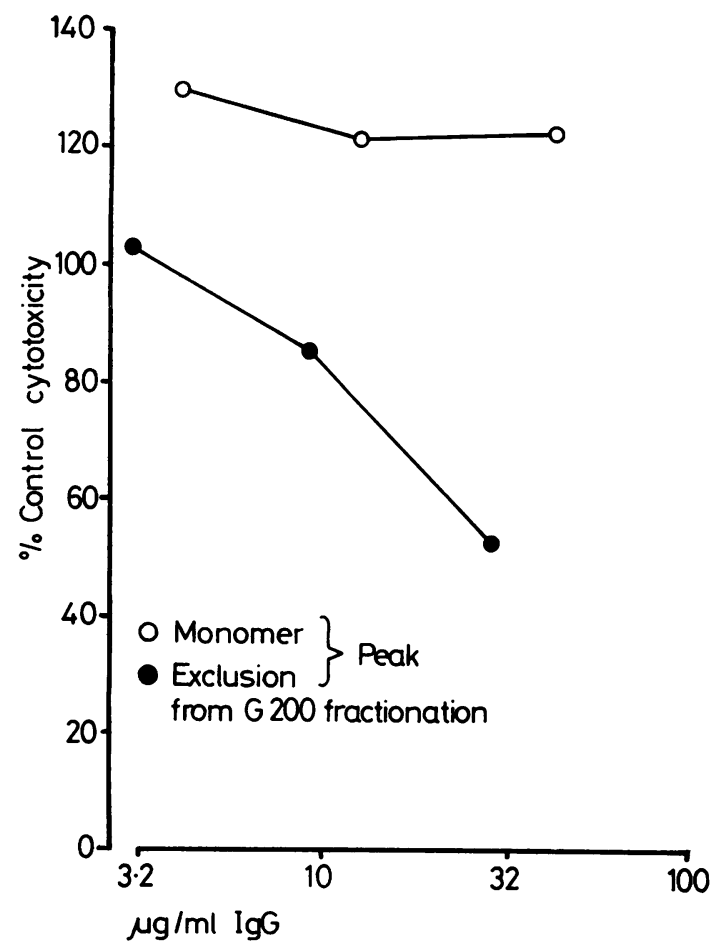

Fig. 2 Human IgG was heated at $63^{\circ} \mathrm{C}$ for 20 minutes and then fractionated on Sephadex G-200. Aggregated, polymeric IgG eluting in the exclusion volume (fractions 30-35 inclusive in Fig. Ia) and monomeric IgG (fractions 42-44 inclusive in Fig. 1a) were tested for their effects on antibody-mediated lymphocyte-induced cytotoxicity. Aggregated $\operatorname{IgG}(\bullet)$ inhibits, while monomeric $\operatorname{IgG}(\mathrm{o})$ enhances cytotoxicity.

We therefore conclude that some two-thirds of patients with AS carry circulating immune complexes in their serum. These complexes seem to be of two molecular sizes: one of intermediate molecular weight $\left(2.2 \times 10^{5}-10^{6}\right.$ daltons) and one of large molecular weight ( $>10^{6}$ daltons). Previous work with this system seemed to indicate that it is most sensitive in detecting complexes of intermediate size (Jewell and MacLennan, 1973), but clearly it is also capable of detecting larger molecular weight complexes.

One finding requires explanation. The amount of complexes detected in original serum and serum diluted with elution buffer and reconcentrated were roughly equal. Thus in the serum shown in Fig. 1c this value was $68.7 \mu \mathrm{g} / \mathrm{ml}$ HAGG equivalents before fractionation but was clearly much greater after fractionation. For the reasons set out above, this is unlikely to be due to aggregation during fractionation. It may be a consequence of the separa. tion of serum into various molecular weight components and in this context it may be relevant note that fractions containing IgG (fractions 42-44, Fig. 1) frequently showed enhancement of ALME: This effect of IgG was confirmed by separafe experiments (Fig. 2). Nevertheless, this study shows that circulating immune complexes are indeed present in the serum of patients with AS.

Two aspects of this new observation remain to be explained. The first concerns the poor correlation between disease activity and presence of circulati $\overrightarrow{\mathrm{ag}}$ complexes, although one patient with inflammatofy peripheral arthritis had the highest concentration $\mathrm{g}_{\mathrm{f}}$ complexes seen in this study. It may be that this failure was due to the relative paucity of extraspinal systemic complications in the group of patients investigated. The difficulty of objectively measurimg disease activity may also have contributed to this failure.

The second aspect concerns the nature of the circulating complexes present in serum and particular the identity of the antigen which theg contain. In AS patients IgG antiglobulin factors ato found (Arana et al., 1975). It is known that such antiglobulins may self-associate to form complexes capable of activating the complement system axd hence capable of initiating inflammation (W chester et al., 1970; Pope et al., 1975). From thes point of view, therefore, they may be similarities ?n immunopathogenesis between AS and rheumato $\overrightarrow{\overrightarrow{0}}$ arthritis. This is supported by family studies lymphocyte responsiveness to IgG in the two diseases (Weisbart et al., 1976).

This study was financed by a grant from Arthritis and Rheumatism Council.

\section{References}

Arana, R. M., Vega, M. T., Porrini, A., and Morteo, O. 앙. (1975). Antiglobulins in ankylosing spondylitis. Journal Rheumatology, 2, 303-307.

Brewerton, D. A., Caffrey, M., Hart, F. D., James, D. C. $\overline{\mathrm{Q}}$, Nichols, A., and Sturrock, R. D. (1973). Anklylosiog spondylitis and HL-A27. Lancet, 2, 904-906.

Hansson, U. B. (1968). Aggregation of human immuno globulin G upon freezing. Acta Chemica Scandinavica, 28 , 483-489.

Jewell, D. P., and MacLennan, I. C. M. (1973). Circulatifing immune complexes in inflammatory bowel disease. Clint and Experimental Immunology, 14, 219-226.

Kinsella, T. D., Espinoza, L., and Vasey, F. B. (19793. Serum complement and immunoglobulin levels in sporadif and familial ankylosing spondylitis. Journal of Rhegmatology, 2, 308-313.

Panayi, G. S. (1976). Antibody-mediated leucocyte cytątoxicity to Chang human liver cells in rheumatoid arthrigis and other diseases. Annals of the Rheumatic Diseases, 35 , 27-31. 
Panayi, G. S., Poston, R. N., and Corrigall, V. (1977). Inhibition of antibody-mediated lymphocyte-induced cytotoxicity by aggregated human immunoglobulin $\mathrm{G}$. Annals of the Rheumatic Diseases, 36, Suppl. 1, 59-63.

Pope, R. M., Teller, D. C., and Mannick, M. (1975). The molecular basis of self-association of IgG-rheumatoid factors. Journal of Immunology, 115, 356-373.

Weisbart, R. H., Morris, R. I., Terasaki, P. I., Bluestone, R., and Goldberg, L. S. (1976). Lymphocyte response to IgG in patients with ankylosing spondylitis and their families. Clinical and Experimental Immunology, 26, 441-448.
Winchester, R. J., Agnello, V., and Kunkel, H. G. (1970). Gamma globulin complexes in synovial fluids of patients with rheumatoid arthritis. Partial characterization and relationship to lowered complement levels. Clinical and Experimental Immunology, 6, 680-706.

Wisløff, F., Michaelson, T. E., and Frøland, S. S. (1974). Inhibition of antibody dependent human lymphocytemediated cytotoxicity by immunoglobulin classes, IgG subclasses, and IgG fragments. Scandinavian Journal of Immunology, 3, 29-32. 